\title{
Analysis of methods commonly used for glycopeptide and oxazolidinone susceptibility testing in Enterococcus faecium isolates
}

\author{
Correspondence \\ Giammarco Raponi \\ giammarco.raponi@uniroma1.it
}

Received 5 October 2009

Accepted 19 February 2010

\author{
Giammarco Raponi, ${ }^{1}$ Maria Cristina Ghezzi, ${ }^{1}$ Giovanni Gherardi, ${ }^{2}$ \\ Giulia Lorino ${ }^{1}$ and Giordano Dicuonzo ${ }^{2}$
}

\author{
${ }^{1}$ Dipartimento di Scienze di Sanità Pubblica, 'Sapienza' University of Rome, Rome, Italy \\ ${ }^{2}$ Dipartimento di Scienze Biomediche, 'Campus Bio-Medico' University, Rome, Italy
}

\section{INTRODUCTION}

Enterococcus species are part of the normal flora of the human gut and other animals. In recent years, enterococci have become important nosocomial pathogens, as they are among the leading causes of bacteraemia in hospitalized patients (Biedenbach et al., 2004). One of the characteristics of these organisms is their resistance to several antimicrobial agents that represent the widely used therapeutic options, such as $\beta$-lactams, macrolides, aminoglycosides and, of particular clinical relevance, glycopeptides. The resistance of enterococci to vancomycin has increased progressively in western countries in recent years (NNIS, 2001; Rice et al., 2004). As reported by the SENTRY surveillance program, resistance to vancomycin is commonly recovered for Enterococcus faecium, being observed in North America and Europe with resistance rates of 93 and $74.1 \%$, respectively (Deshpande et al., 2007). The introduction of linezolid into clinical practice has offered an alternative therapeutic option for the successful treatment of glycopeptideresistant enterococci, especially E. faecium (Falagas \& Vardakas, 2008; Linden, 2002; Scheetz et al., 2006). However, the prompt emergence of linezolid-resistant strains of E. faecium has been reported (Gonzales et al., 2001; Jones et al., 2007). Therefore, correct identification of strains and determination of their susceptibility to glycopeptides and oxazolidinone are fundamental for the treatment of infections caused by multiresistant strains of E. faecium.
The purpose of this study was to assess the performance of methods commonly used in susceptibility testing for teicoplanin, vancomycin and linezolid. Antimicrobial susceptibilities obtained from the bioMérieux Vitek 2 and BD Phoenix systems were compared with those obtained by a disc diffusion test, Etest and broth microdilution determination of MIC against clinical isolates of E. faecium. Resistance to glycopeptides was then correlated with the carriage of $v a n A$ and $v a n B$ genes, and resistance to linezolid with the presence of the G2576T mutation in domain V of the $23 \mathrm{~S}$ rRNA gene by molecular methods.

\section{METHODS}

Strain collection. Thirty strains of E. faecium were collected during 2007 from clinical specimens from patients hospitalized in different wards of the 'Azienda Policlinico Umberto I' academic hospital of Rome, Italy. The strains were representative of a single infective episode and were isolated from blood and central venous catheters (ten strains), the urogenital tract (seven strains), wound infections (six strains), bile (two strains) and swabs of various anatomical sites (five strains). The strains were collected if they displayed an MIC for teicoplanin and/or vancomycin of $\geqslant 2 \mu \mathrm{g} \mathrm{ml} \mathrm{m}^{-1}$ during routine screening, performed in the diagnostic laboratory by the Vitek 2 test (bioMérieux; software version 4.01). Only one strain (L228) was found to be resistant to linezolid. Bacterial strains were adhered to porous beads (Microbank; Pro-lab Diagnostics) and stored at $-80{ }^{\circ} \mathrm{C}$ until further analysis.

Identification and antimicrobial susceptibility testing. The strains were analysed by the Vitek 2 system, using ID-GPC cards 
for identification and by both P535 and P534 cards for susceptibility testing, and by the Phoenix system (BD Diagnostic Systems) using PMIC panels, following the manufacturer's recommendations. Strain identification was verified by the biochemical reactions of the API 20 STREP strips (bioMérieux). Etest (AB Biodisk), broth microdilution determination of MIC and disc diffusion test were also used to check susceptibility to teicoplanin, vancomycin and linezolid, following the manufacturer's instructions and Clinical and Laboratory Standards Institute guidelines. Staphylococcus aureus ATCC 25923 was routinely used as a quality control strain for the disc diffusion tests, and Enterococcus faecalis ATCC 29212 was used for broth microdilution and the automated methods (CLSI 2006, 2007). The susceptibility of E. faecium ATCC 19434 to the test drugs was also tested as a control for all the susceptibility tests studied. Each isolate resistant to glycopeptides was assigned to a resistance phenotype as follows: strains resistant to both vancomycin and teicoplanin were ascribed to the VanA phenotype; strains resistant to vancomycin but susceptible to teicoplanin were assigned to the VanB phenotype (Deshpande et al., 2007). The results of susceptibility tests for vancomycin were considered to be false-positives for those strains non-susceptible to the drug (either resistant or with intermediate susceptibility) in the absence of vanA gene carriage, whilst false-negative test results were defined for those strains that were susceptible to vancomycin in the presence of vanA gene carriage.

\section{Amplification of vanA and vanB genes and detection of the} G2576T mutation in the 23S rRNA gene. PCR was used to detect the presence of the vanA and $v a n B$ resistance genes, using a PCR Reagent System (Gibco-BRL). Reactions were carried out in a PerkinElmer 480 thermal cycler in a $50 \mu \mathrm{l}$ volume containing: $1.25 \mathrm{U}$ Taq polymerase, $0.2 \mathrm{mM}$ each dNTP, $1.5 \mathrm{mM} \mathrm{MgCl}_{2}, 1 \times$ PCR buffer, $1 \mu \mathrm{g}$ each primer and $0.1 \mu \mathrm{g}$ template DNA. PCR was performed for 35 cycles of $1 \mathrm{~min}$ at $94{ }^{\circ} \mathrm{C}, 1 \mathrm{~min}$ at $50{ }^{\circ} \mathrm{C}$ and $1 \mathrm{~min}$ at $72{ }^{\circ} \mathrm{C}$, followed by a final extension step at $72{ }^{\circ} \mathrm{C}$ for $10 \mathrm{~min}$. Primers specific for regions flanking Tn1546, vanRS, vanSH, vanHaX, vanXY and vanYZ were used to amplify this area, as described previously (Alam et al., 2001; Clark et al., 1993; Donabedian et al., 2000; Thal et al., 1998).

The molecular basis of linezolid resistance has been identified as a single G2576T nucleotide substitution in multiple alleles encoding the $23 \mathrm{~S}$ rRNA gene, which generates a new restriction site for the NheI restriction enzyme. The presence of the G2576T mutation (Escherichia coli numbering scheme) in domain $\mathrm{V}$ of the $23 \mathrm{~S}$ rRNA gene was detected as described previously (Bonora et al., 2006). An internal fragment (746 bp) of the $23 \mathrm{~S}$ rRNA gene, including the $\mathrm{V}$ domain, was amplified by PCR. Primers designed on the basis of the sequence of the 23S rRNA gene for E. faecium (GenBank accession no. AF432914) were 23Sfor (5'-TAGTACCTGTGAAGATGCAGG-3') and 23 Srev ( $5^{\prime}$-CACACTTAGATGCTTTCAGCG-3'). The cycling conditions were as follows: initial denaturation at $94{ }^{\circ} \mathrm{C}$ for $5 \mathrm{~min}$, followed by 30 cycles of $94{ }^{\circ} \mathrm{C}$ for $1 \mathrm{~min}, 50{ }^{\circ} \mathrm{C}$ for $30 \mathrm{~s}$ and $72{ }^{\circ} \mathrm{C}$ for $1 \mathrm{~min}$, with a final extension step at $72{ }^{\circ} \mathrm{C}$ for $5 \mathrm{~min}$. Samples $(5 \mu \mathrm{l})$ of the PCR product were digested with $10 \mathrm{U}$ NheI enzyme (Invitrogen Life Technologies) at $37{ }^{\circ} \mathrm{C}$ for $4 \mathrm{~h}$ and separated on a $2 \%$ agarose gel in $1 \times$ Tris/acetate/EDTA buffer. The $746 \mathrm{bp}$ band corresponding to the undigested amplification product represented the wild-type, and the presence of two bands of 557 and $189 \mathrm{bp}$ corresponded to the products of NheI digestion and indicated the mutant alleles responsible for linezolid resistance.

\section{RESULTS AND DISCUSSION}

The results of Vitek 2 and Phoenix agreed with the API 20 STREP system in identifying the collected strains as $E$. faecium. All strains were susceptible to ampicillin and quinupristin/dalfopristin by all of the methods tested.

The Vitek 2 results indicated that only strain L117 was resistant to teicoplanin (Table 1), and the results obtained with P535 cards differed from those of P534 cards for two strains (L103 and L210) recognized as intermediate. The MIC values obtained by Vitek 2 fully agreed with those observed by the broth microdilution test for two strains only (L228 and L259), whilst the MICs for the remaining strains were at least a twofold dilution lower than those obtained by the broth microdilution test. Furthermore, 12 teicoplanin-resistant strains with MICs $\geqslant 16 \mu \mathrm{g} \mathrm{ml}^{-1}$ in the broth microdilution test were reported by Vitek 2 to be in the susceptibility range with MICs $\leqslant 2 \mu \mathrm{g} \mathrm{ml}^{-1}$.

The susceptibility tests performed by the Phoenix test showed that 12 strains were susceptible to teicoplanin, one strain (L89) was intermediate and the remaining 17 strains were resistant to teicoplanin ( $\mathrm{MIC} \geqslant 16 \mu \mathrm{g} \mathrm{ml}^{-1}$ ). The MIC values obtained by the Phoenix test fully agreed with those observed by the broth microdilution test for 21 strains, and differed for eight strains by one or two twofold dilutions, even though they were in the same range of susceptibility. A single strain (L118) was shown to be susceptible by the Phoenix test $\left(\mathrm{MIC}=8 \mu \mathrm{g} \mathrm{ml}^{-1}\right.$ ), whereas the broth microdilution test reported the strain to be resistant, with an MIC of $32 \mu \mathrm{g} \mathrm{ml}^{-1}$. The results of the Phoenix test agreed with those of Vitek 2 for 13/30 isolates (12 susceptible strains and one resistant strain), even though the MIC values differed.

In comparison with the broth microdilution test, both the Etest and disc diffusion test agreed in classifying 11 strains as susceptible, two strains as intermediate and 14 as resistant. However, MICs obtained by Etest differed from the values observed by broth microdilution (more than two twofold dilutions) in seven strains, even though they were in the same range of resistance. By comparing all the results in terms of resistance rates, it was found that $3-3.4 \%$ of the strains were reported as resistant to teicoplanin by the Vitek 2 system, whereas the resistance rates of the other methods ranged from $50 \%$ for the disc diffusion test to $57.6 \%$ for the Phoenix test (Fig. 1).

The Vitek 2 P535 cards revealed that six strains were susceptible to vancomycin (MIC $\leqslant 1 \mu \mathrm{g} \mathrm{ml}^{-1}$ ) and 24 were resistant (MIC $\geqslant 32 \mu \mathrm{g} \mathrm{ml}^{-1}$; Table 1). Despite different MIC values, these results agreed with those obtained with the broth microdilution test for 28 strains in classifying the strains as susceptible or not susceptible. Two strains (L1 and L228) reported as having an MIC of $1 \mu \mathrm{g} \mathrm{ml}^{-1}$ by the Vitek 2 P535 cards showed different MICs by broth microdilution (32 and $16 \mu \mathrm{g} \mathrm{ml}^{-1}$, respectively).

The analysis performed with Vitek 2 P534 cards showed that 13 strains were susceptible and 17 were resistant to the drug. Once again, despite different MIC values, these results agreed with those obtained with the broth dilution test for 21 strains in classifying the strains as susceptible or 
Table 1. Results of antimicrobial susceptibility testing for teicoplanin, vancomycin and linezolid and molecular analysis of the 30 clinical isolates of Enterococcus faecium

\begin{tabular}{|c|c|c|c|c|c|c|c|c|c|c|c|c|c|c|c|c|c|c|c|c|}
\hline \multirow{2}{*}{$\begin{array}{l}\text { Study } \\
\text { code }\end{array}$} & \multicolumn{6}{|c|}{ Teicoplanin } & \multicolumn{6}{|c|}{ Vancomycin } & \multicolumn{6}{|c|}{ Linezolid } & \multicolumn{2}{|c|}{ Molecular tests } \\
\hline & $\begin{array}{l}\text { Vitek } 2 \\
\text { P535 }^{*}\end{array}$ & $\begin{array}{l}\text { Vitek } 2 \\
\text { P534 }^{\star}\end{array}$ & $\begin{array}{l}\text { Phoenix } \\
\text { PMIC }^{*}\end{array}$ & Etest $^{*}$ & $\begin{array}{c}\text { Broth } \\
\text { micro- } \\
\text { dilution }\end{array}$ & $\begin{array}{c}\text { Disc } \\
\text { diffusion } \dagger\end{array}$ & $\begin{array}{l}\text { Vitek } 2 \\
\text { P535* }^{*}\end{array}$ & $\begin{array}{l}\text { Vitek } 2 \\
\text { P534 }^{\star}\end{array}$ & $\begin{array}{l}\text { Phoenix } \\
\text { PMIC }^{*}\end{array}$ & Etest $^{*}$ & $\begin{array}{c}\text { Broth } \\
\text { micro- } \\
\text { dilution* }\end{array}$ & $\begin{array}{c}\text { Disc } \\
\text { diffusion } \dagger\end{array}$ & $\begin{array}{l}\text { Vitek } 2 \\
\text { P535 }^{\star}\end{array}$ & $\begin{array}{l}\text { Vitek } 2 \\
\text { P534 }^{*}\end{array}$ & $\begin{array}{l}\text { Phoenix } \\
\text { PMIC }^{*}\end{array}$ & Etest $^{*}$ & $\begin{array}{c}\text { Broth } \\
\text { micro- } \\
\text { dilution }^{*}\end{array}$ & $\begin{array}{c}\text { Disc } \\
\text { diffusion } \dagger\end{array}$ & $\operatorname{van} A \ddagger$ & $\begin{array}{c}23 S \\
\text { rRNA } \\
\text { mutation } \ddagger\end{array}$ \\
\hline L1 & 2 & 1 & 4 & 4 & 4 & $\mathrm{~s}$ & 1 & 1 & $>16$ & 32 & 32 & $\mathrm{R}$ & 2 & 2 & 2 & 4 & 6 & $\mathrm{~s}$ & + & - \\
\hline L23 & 2 & 1 & $>16$ & 64 & 128 & $\mathrm{R}$ & 32 & 32 & $>16$ & 256 & 256 & $\mathrm{R}$ & 2 & 2 & 2 & 2 & 3 & S & + & - \\
\hline L39 & 4 & 2 & $>16$ & 48 & 128 & $\mathrm{R}$ & 32 & 32 & $>16$ & 256 & 256 & $\mathrm{R}$ & 2 & 2 & 2 & 2 & 3 & S & + & - \\
\hline L45 & 1 & 1 & $>16$ & 96 & 128 & $\mathrm{R}$ & 32 & 32 & $>16$ & 256 & 256 & $\mathrm{R}$ & 2 & 2 & 2 & 3 & 3 & $\mathrm{~s}$ & + & - \\
\hline L64 & 4 & 1 & 8 & 4 & 4 & S & 32 & 1 & $>16$ & 256 & 256 & $\mathrm{R}$ & 2 & 2 & 2 & 3 & 3 & s & + & - \\
\hline L73 & 4 & 0.5 & 8 & 4 & 4 & s & 32 & 1 & $>16$ & 256 & 256 & $\mathrm{R}$ & 2 & 2 & 2 & 3 & 3 & s & + & - \\
\hline L80 & 4 & 1 & 8 & 4 & 4 & S & 64 & 1 & $>16$ & 32 & 32 & $\mathrm{R}$ & 2 & 2 & 2 & 3 & 3 & S & + & - \\
\hline L89 & 4 & 1 & 16 & 8 & 16 & I & 64 & 1 & $>16$ & 32 & 32 & $\mathrm{R}$ & 2 & 2 & 2 & 3 & 3 & S & + & - \\
\hline L98 & 1 & 4 & $>16$ & 64 & 128 & $\mathrm{R}$ & 32 & 32 & $>16$ & 256 & 256 & $\mathrm{R}$ & 2 & 2 & 2 & 3 & 3 & S & + & - \\
\hline L99 & 1 & 1 & $>16$ & 32 & 128 & $\mathrm{R}$ & 32 & 32 & $>16$ & 256 & 256 & $\mathrm{R}$ & 2 & 2 & 2 & 2 & 3 & S & + & - \\
\hline L101 & 1 & 1 & $>16$ & 32 & 128 & $\mathrm{R}$ & 32 & 32 & $>16$ & 256 & 256 & $\mathrm{R}$ & 2 & 2 & 2 & 2 & 1.5 & S & + & - \\
\hline L103 & 16 & 4 & $>16$ & 24 & 32 & $\mathrm{R}$ & 32 & 32 & $>16$ & 256 & 256 & $\mathrm{R}$ & 2 & 2 & 2 & 3 & 3 & S & + & - \\
\hline L117 & 32 & 32 & $>16$ & 32 & 128 & $\mathrm{R}$ & 32 & 32 & $>16$ & 256 & 256 & $\mathrm{R}$ & 2 & 2 & 2 & 3 & 3 & S & + & - \\
\hline L118 & 4 & 2 & 8 & 16 & 32 & I & 64 & 1 & $>16$ & 32 & 32 & $\mathrm{R}$ & 2 & 2 & 2 & 4 & 3 & $\mathrm{~S}$ & + & - \\
\hline L121 & 4 & 1 & 8 & 1 & 8 & $\mathrm{~S}$ & 1 & 1 & $>16$ & 1.5 & 2 & S & 2 & 2 & 2 & 2 & 3 & S & - & - \\
\hline L129 & 16 & 16 & $>16$ & 96 & 128 & $\mathrm{R}$ & 32 & 32 & $>16$ & 256 & 256 & $\mathrm{R}$ & 2 & 2 & 2 & 2 & 1.5 & S & + & - \\
\hline L152 & 4 & 1 & 8 & 4 & 4 & S & 64 & 1 & $>16$ & 8 & 32 & $\mathrm{R}$ & 2 & 2 & 2 & 2 & 3 & $\mathrm{~S}$ & + & - \\
\hline L157 & 0.5 & 4 & $<1$ & 4 & 4 & S & 1 & 1 & $<1$ & 1 & 2 & S & 2 & 2 & 2 & 4 & 3 & S & - & - \\
\hline L158 & 1 & 4 & $<1$ & 4 & 4 & S & 1 & 1 & $<1$ & 1.5 & 2 & S & 2 & 2 & 2 & 3 & 3 & S & - & - \\
\hline L201 & 4 & 1 & 8 & 4 & 4 & S & 64 & 1 & $>16$ & 8 & 32 & $\mathrm{R}$ & 2 & 2 & 2 & 3 & 3 & S & + & - \\
\hline L210 & 16 & 4 & $>16$ & 64 & 128 & $\mathrm{R}$ & 32 & 32 & $>16$ & 256 & 256 & $\mathrm{R}$ & 4 & 4 & 4 & 4 & 3 & S & + & - \\
\hline L212 & 4 & 1 & $>16$ & 64 & 64 & $\mathrm{R}$ & 32 & 32 & $>16$ & 32 & 32 & $\mathrm{R}$ & 2 & 2 & 2 & 2 & 3 & S & + & - \\
\hline L228 & 1 & 1 & $<1$ & 6 & 1 & S & 1 & 1 & $<1$ & 24 & 16 & I & $>8$ & $>8$ & 2 & 4 & 24 & $\mathrm{R}$ & - & + \\
\hline L235 & 4 & 1 & $>16$ & 48 & 128 & $\mathrm{R}$ & 32 & 32 & $>16$ & 256 & 256 & $\mathrm{R}$ & 2 & 2 & 2 & 2 & 1.5 & S & + & - \\
\hline L236 & 4 & 1 & $>16$ & 48 & 128 & $\mathrm{R}$ & 32 & 32 & $>16$ & 256 & 256 & $\mathrm{R}$ & 4 & 2 & 2 & 4 & 1.5 & S & + & - \\
\hline L246 & 1 & 1 & $>16$ & 48 & 128 & $\mathrm{R}$ & 32 & 32 & $>16$ & 256 & 256 & $\mathrm{R}$ & 2 & 2 & 2 & 2 & 3 & S & + & - \\
\hline L249 & 4 & 4 & $>16$ & 24 & 16 & I & 32 & 64 & $>16$ & 32 & 32 & $\mathrm{R}$ & 2 & 2 & 2 & 2 & 2 & S & + & - \\
\hline L251 & 4 & 4 & $>16$ & 128 & 128 & $\mathrm{R}$ & 32 & 32 & $>16$ & 256 & 256 & $\mathrm{R}$ & 2 & 2 & 2 & 2 & 3 & S & + & - \\
\hline L257 & 4 & 4 & $>16$ & 12 & 128 & I & 32 & 64 & $>16$ & 32 & 32 & $\mathrm{R}$ & 2 & 2 & 2 & 2 & 1.5 & S & + & - \\
\hline L259 & 4 & 4 & $<1$ & 4 & 4 & S & 1 & 1 & $<1$ & 1 & 1 & S & 2 & 2 & 2 & 2 & 3 & S & - & - \\
\hline
\end{tabular}

${ }^{*}$ Results of antimicrobial testing $\left(\mu \mathrm{g} \mathrm{ml}{ }^{-1}\right)$

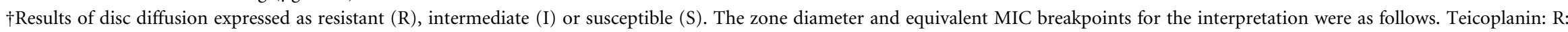

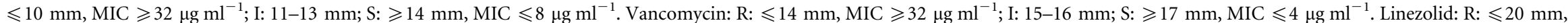
MIC $\geqslant 8 \mu \mathrm{g} \mathrm{ml}^{-1}$; I: $21-22 \mathrm{~mm} ; \mathrm{S}: \geqslant 23 \mathrm{~mm}, \mathrm{MIC} \leqslant 2 \mu \mathrm{g} \mathrm{ml}^{-1}$.

$¥$ The presence of the $v a n A$ gene and/or the $23 \mathrm{~S}$ rRNA gene mutation is indicated as positive $(+)$ or negative $(-)$. 


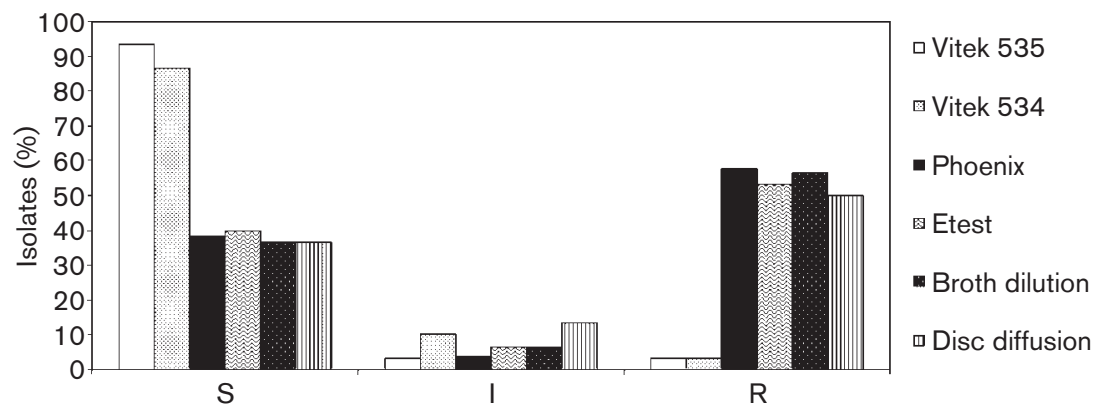

Fig. 1. Susceptibility to teicoplanin of 30 Enterococcus faecium isolates. Results are expressed as the percentage of susceptible $(\mathrm{S})$, intermediate $(\mathrm{I})$ and resistant $(\mathrm{R})$ strains.

not susceptible. However, nine strains, reported by the Vitek 2 P534 cards as having an MIC of $1 \mu \mathrm{g} \mathrm{ml}^{-1}$, showed MICs of $\geqslant 16 \mu \mathrm{g} \mathrm{ml}$ when tested by the broth microdilution test.

The susceptibility tests performed by the Phoenix test reported four strains as susceptible and 26 as resistant. The MIC values agreed with those reported by the broth dilution test for all but two strains: strain L121 displayed an MIC of $>16 \mu \mathrm{g} \mathrm{ml}^{-1}$ by the Phoenix test whilst the broth dilution test gave an MIC of $2 \mu \mathrm{g} \mathrm{ml}^{-1}$, and strain L228 gave an MIC of $<1 \mu \mathrm{g} \mathrm{ml}^{-1}$ with the Phoenix test and $16 \mu \mathrm{g} \mathrm{ml}^{-1}$ with the broth microdilution test.

The Etest and broth microdilution method gave the same MIC values for all but two strains (L152 and L201), where the Etest showed an MIC in the range of intermediate susceptibility $\left(8 \mu \mathrm{g} \mathrm{ml}^{-1}\right)$ whilst the broth microdilution test gave an MIC of $32 \mu \mathrm{g} \mathrm{ml}^{-1}$. In all instances, the broth microdilution method agreed with the disc diffusion test in defining the strains as susceptible, intermediate or resistant to vancomycin. Comparing the results in terms of resistance rates, it was evident that $56.7 \%$ of the strains showed resistance to vancomycin when tested by Vitek 2 P534 cards, whilst the other tests produced resistance rates ranging from $80 \%$ for the Vitek 2 (P535) test to $86.7 \%$ for the Phoenix test (Fig. 2).

Twenty-four strains were reported as susceptible to linezolid by all the methods used (MIC $\leqslant 3 \mu \mathrm{g} \mathrm{ml}^{-1}$; Table 1). Vitek 2 P535 cards revealed that 27 strains were susceptible to the drug, two strains were found with intermediate susceptibility $\left(\mathrm{MIC}=4 \mu \mathrm{g} \mathrm{m} \mathrm{m}^{-1}\right)$ and one strain was reported as resistant (L228, MIC $\geqslant 8 \mu \mathrm{g} \mathrm{ml}^{-1}$ ). The analysis performed with Vitek 2 P535 cards agreed with the P534 cards for the 27 susceptible strains, the single resistant strain (L228) and for one isolate with intermediate susceptibility (L210), but disagreed for strain L236 by finding the MIC to be $\leqslant 2 \mu \mathrm{g} \mathrm{ml}^{-1}$ by the P534 cards (intermediate by $\mathrm{P} 535$ cards; $\mathrm{MIC}=4 \mu \mathrm{g} \mathrm{ml} \mathrm{m}^{-1}$ ). The Phoenix test agreed with the Vitek 2 P534 cards for 28 susceptible isolates and for one intermediate strain, but reported a susceptible result for strain L228, which was resistant by the two Vitek 2 P534 and P535 cards. The Etest and broth microdilution test agreed in defining strain L1 as intermediate, but four strains that were reported to be intermediate by the Etest were susceptible by broth microdilution. Strain L228 showed intermediate resistance by the Etest, but was resistant by broth microdilution $\left(\mathrm{MIC}=24 \mu \mathrm{g} \mathrm{ml}^{-1}\right)$ and disc diffusion. Comparing the results in terms of susceptibility rates, it appeared that most of the strains were reported as susceptible (ranging from $83.3 \%$ for the Etest to $96.6 \%$ for the Phoenix and disc diffusion tests; Fig. 3). Much higher variability was observed for the strains that were reported as having intermediate susceptibility, with values ranging from $0 \%$ (disc diffusion) to $16.7 \%$ (Etest). The resistance rate was attributable to strain L228, which was reported as resistant by the Vitek 2 (P534 and P535 cards), broth microdilution and disc diffusion tests.

The presence of the $v a n A$ and $v a n B$ genes in the E. faecium strains was analysed by PCR. Twenty-five strains carried

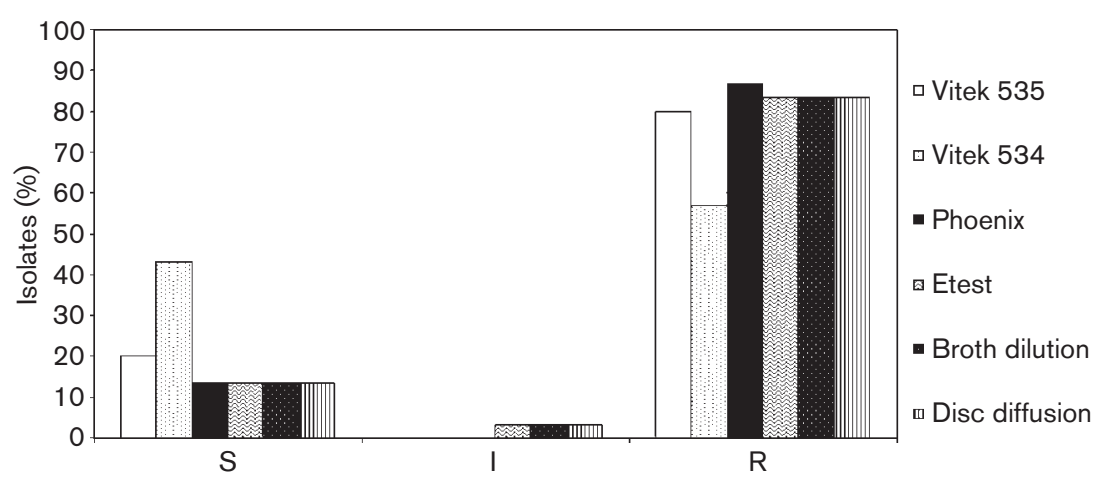

Fig. 2. Susceptibility to vancomycin of 30 Enterococcus faecium isolates. Results are expressed as the percentage of susceptible $(\mathrm{S})$, intermediate $(\mathrm{I})$ and resistant (R) strains. 


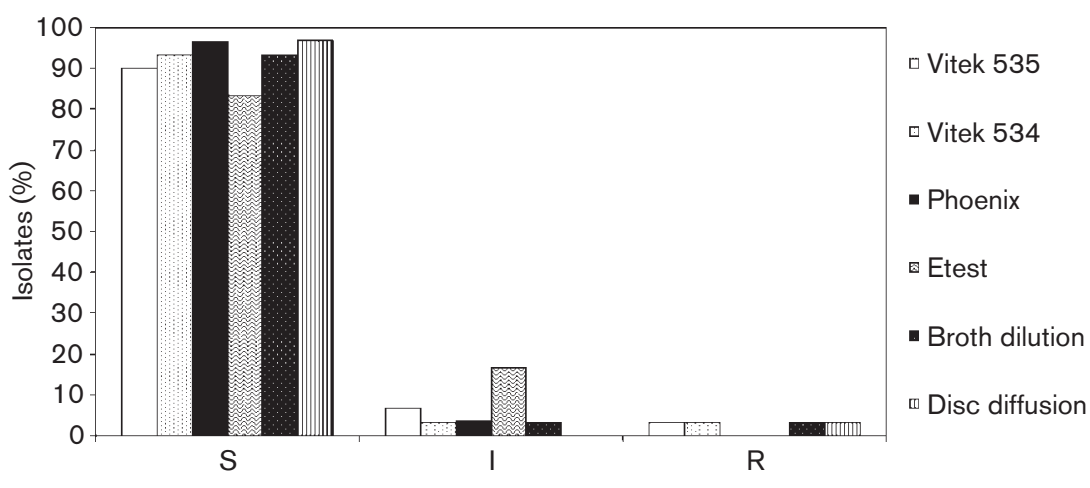

Fig. 3. Susceptibility to linezolid of 30 Enterococcus faecium isolates. Results are expressed as the percentage of susceptible $(S)$, intermediate $(I)$ and resistant $(R)$ strains. the vanA gene whilst no strain carried $\operatorname{vanB}$ (Table 1). Only two strains carrying vanA (L117 and L129) were univocally assigned to the VanA phenotype by all the methods. However, the number of strains showing the VanA phenotype reached 19 when the results obtained by the Vitek 2 test were excluded. Six strains carrying van $A$ (L1, L64, L73, L80, L152 and L201) showed the VanB phenotype (resistant to vancomycin and susceptible to teicoplanin), but the Vitek 2 P534 cards reported these strains as susceptible to vancomycin. All strains carrying vanA were non-susceptible to vancomycin when tested by the Phoenix, Etest, disc diffusion and broth microdilution methods. However, false-positive results, indicating strains non-susceptible to vancomycin in the absence of vanA gene carriage, occurred for strain L121, resistant to vancomycin by the Phoenix test, and strain L228, which was reported as having intermediate susceptibility for vancomycin when tested by the Etest, broth microdilution and disc diffusion tests (Table 1). Furthermore, one false-negative result, indicating strains susceptible to vancomycin in the presence of the vanA gene, was observed with the Vitek 2 P535 cards, and Vitek 2 P534 cards reported eight strains carrying the vanA gene as susceptible, indicating $30 \%$ false-negative results.

Experiments were performed to detect whether the collected E. faecium strains carried the G2576T mutation in the $\mathrm{V}$ domain of the 23S rRNA gene responsible for linezolid resistance (Fig. 4). A band of 746 bp corresponding to the undigested amplification products was found in all the collected strains. A band of 746 bp together with two bands of 557 and $189 \mathrm{bp}$ corresponding to the two products of NheI digestion were found only in strain L228, indicating the presence of both wild-type and mutant alleles, thus confirming the linezolid resistance of this strain.

E. faecium has progressively changed from an innocent commensal organism to a feared multidrug-resistant hospital-adapted pathogen. Therefore, accurate identification and reliable antimicrobial susceptibility testing may be of paramount importance in the clinical management of infections caused by this micro-organism.

A recent paper reported difficulties in the correct identification of E. faecium by Vitek 2, Phoenix and API Rapid ID 32 STREP (bioMérieux) in the case of strains with low-level inducible resistance to vancomycin (Pendle et al., 2008). The strain collection in our study was mostly composed of susceptible or fully vancomycin-resistant strains, and even in the presence of low-level resistance to vancomycin (strain $\mathrm{L} 228, \mathrm{MIC}=16 \mu \mathrm{g} \mathrm{ml} \mathrm{m}^{-1}$ by broth dilution), our results confirmed previous observations (Abele-Horn et al., 2006) on the univocal identification accomplished by the Vitek 2, Phoenix and API 20 STREP systems. However, our study showed variability among the tests used for the determination of antimicrobial susceptibility, especially for the glycopeptides. The presence of $v a n A$ and/or vanB genes in the bacterial genome can be taken as a reference indicator for resistance to glycopeptides (Deshpande et al., 2007). In our study, 25 strains carried $v a n A$, whilst no strain harboured vanB. Therefore, it could be expected that these strains, expressing the VanA phenotype in the various antimicrobial susceptibility tests, were resistant to both teicoplanin and vancomycin

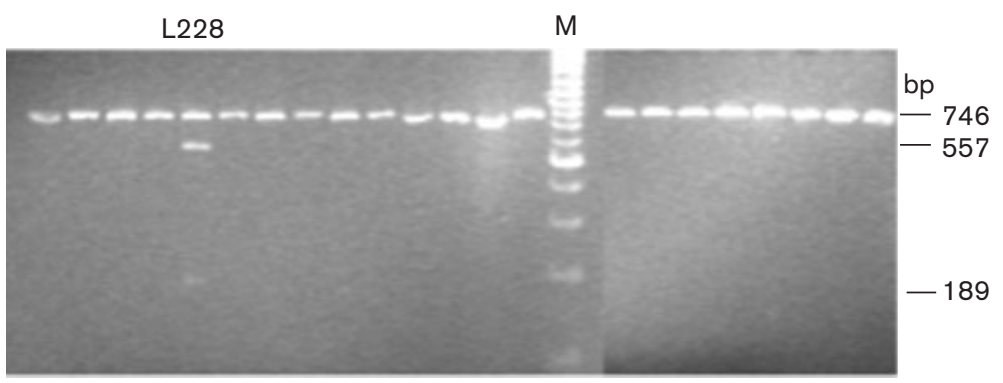

Fig. 4. PCR-RFLP analysis of the $23 S$ rRNA gene of strain L228 and of 21 other strains randomly taken from the collection. Nhel restriction enzyme digestion of the internal fragment of $746 \mathrm{bp}$ of the 23S rRNA gene generated two bands of 557 and 189 bp (faint band) in strain L228, thus confirming linezolid resistance. Lane M, 100 bp ladder. 
(Deshpande et al., 2007). In our experiments, this hypothesis was confirmed only for two strains carrying the vanA gene, which were univocally reported as resistant to both teicoplanin and vancomycin by all methods used. This observation was due to the results obtained with Vitek 2 , which showed the highest degree of vanA-positive teicoplanin-susceptible strains, a feature that was not confirmed by the other methods used. Indeed, excluding the results of Vitek 2, the number of strains carrying the vanA gene and displaying the VanA phenotype reached 19. Six strains carrying vanA were reported as susceptible to teicoplanin by all the methods used and were resistant to vancomycin when tested by the Phoenix, Etest, broth microdilution and disc diffusion tests. Therefore, again excluding the results of Vitek 2, these isolates could be assigned as displaying the $\mathrm{VanB}$ phenotype/vanA genotype, referring to strains susceptible to teicoplanin and resistant to vancomycin, despite vanA gene carriage (Deshpande et al., 2007). VanB phenotype/vanA genotype E. faecium strains have been reported (Lee et al., 2004), and a recent paper described similar strains of E. faecium which also had heterogeneous expression of teicoplanin resistance, as witnessed by the growth of colonies in the elliptic inhibition zone of the Etest susceptibility testing (Park et al., 2008). However, this latter feature was not observed in our experiments, as none of the VanB phenotype/vanA genotype E. faecium strains showed heterogeneous resistance to teicoplanin in the Etest. Therefore, summarizing the teicoplanin susceptibility data observed with the various methods used and the correlation with vanA gene carriage, including the possibility of matching the $\operatorname{Van} B$ phenotype/vanA genotype, it was evident that the Etest and disc diffusion tests agreed with the broth microdilution test in indicating resistance, the Phoenix test displayed one false-negative result and the Vitek 2 test presented a high degree of false-negative results, regardless of the type of card used. Our observations in determining teicoplanin resistance agreed with those of other authors (GarciaGarrote et al., 2000; van den Braak et al., 2001), even though the failure of Vitek 2 to detect teicoplanin resistance was reported at a much lower degree (Kobayashi et al., 2004), and improved detection of teicoplanin resistance has been envisaged (Abele-Horn et al., 2006). However, the susceptibility testing of vancomycin showed that comparable performances were provided by the Phoenix, Etest, broth dilution and disc diffusion tests (one false-positive result each), and that Vitek 2 generated several false-negative results, reporting susceptibility to vancomycin in strains carrying the vanA gene (one strain with P534 cards and eight strains with P535 cards). Our results were comparable to those obtained by Abele-Horn et al. (2006), who reported an overall sensitivity of $98.5 \%$ for the detection of vanA enterococci with the same Vitek 2 P534 cards, but highly discordant results using P535 cards, when the sensitivity dropped to $68 \%$.

The susceptibility testing of linezolid showed a lower degree of variability among all the methods used, as most of the strains were reported as susceptible to the drug (22/ 30 strains with MIC values ranging from 1.5 to $3 \mu \mathrm{g} \mathrm{ml}^{-1}$ ). However, among the methods used, differences emerged both in recognition of the resistant strain and in the determination of strains expressing intermediate susceptibility. These observations partly agreed with those of Tenover et al. (2007), who found variability in detecting resistance of E. faecium to linezolid among various methods including those reported in our work. Carriage of the G2576T mutation in domain V of the 23S rRNA gene of Enterococcus has been associated with resistance to linezolid (Marshall et al., 2002; Ruggero et al., 2003; Tenover et al., 2007). In our experiments, the unique strain showing this mutation was recognized as resistant by Vitek 2 as well as by the broth dilution and disc diffusion tests, but not by the Phoenix test, which reported the strain as susceptible. The Etest reported the strain as having intermediate susceptibility, possibly due to the intrinsic difficulties in interpreting the $80 \%$ growth inhibition end point by visual examination, with the Etest method rounding up the MIC. Indeed, Etest was the method that reported the highest number of strains with intermediate susceptibility to linezolid. It has been reported that the level of resistance to linezolid correlates with the number of $23 \mathrm{~S}$ rRNA genes containing the mutation and that different alleles can be found in the same linezolid-resistant strain (Marshall et al., 2002; Ruggero et al., 2003). The density of the $746 \mathrm{bp}$ band of the undigested amplification products correlated with the number of mutated copies: strains with lower MIC values for linezolid had a 746 bp band with a higher density, whilst strains with higher MICs for linezolid displayed a lower density band, depending on the number of copies of the mutated gene (Rice et al., 2004). However, we did not observe any major difference in the density of the $746 \mathrm{bp}$ bands of the test strains, especially in those strains reported as having intermediate susceptibility, and the definitive demonstration of linezolid resistance was observed in the strain that produced the two products of NheI digestion (L228). Finally, it is noteworthy that, although this strain bore the G2576T mutation, it did not carry the vanA gene.

In conclusion, the results of glycopeptide and linezolid susceptibility testing of E. faecium produced by some of the more widely used methods need careful interpretation, and integration of different methods should be implemented by the clinical microbiologist for the best therapeutic approach.

\section{REFERENCES}

Abele-Horn, M., Hommers, L., Trabold, R. \& Frosch, M. (2006). Validation of VITEK 2 version 4.01 software for detection, identification, and classification of glycopeptides-resistant enterococci. J Clin Microbiol 44, 71-76.

Alam, M. R., Donabedian, S., Brown, W., Gordon, J., Chow, J. W., Zervos, M. J. \& Hershberger, E. (2001). Heteroresistance to vancomycin in Enterococcus faecium. J Clin Microbiol 39, 3379-3381. 
Biedenbach, D. J., Moet, G. J. \& Jones, R. N. (2004). Occurrence and antimicrobial resistance pattern comparisons among bloodstream infection isolates from the SENTRY Antimicrobial Surveillance Program (1997-2002). Diagn Microbiol Infect Dis 50, 59-69.

Bonora, M. G., Solbiati, M., Stepan, E., Zorzi, A., Luzzani, A., Catania, M. R. \& Fontana, R. (2006). Emergence of linezolid resistance in the vancomycin-resistant Enterococcus faecium multilocus sequence typing C1 epidemic lineage. J Clin Microbiol 44, 1153-1155.

Clark, N. C., Cooksey, R. C., Hill, B. C., Swenson, J. M. \& Tenover, F. C. (1993). Characterization of glycopeptide-resistant enterococci from U.S. hospitals. Antimicrob Agents Chemother 37, 2311-2317.

CLSI (2006). Performance Standards for Antimicrobial Susceptibility Tests; Approved Standard, 9th edn, M2-A9. Wayne, PA: Clinical and Laboratory Standards Institute.

CLSI (2007). Performance Standards for Antimicrobial Susceptibility Testing, 17th Informational Supplement, M100-S17. Wayne, PA: Clinical and Laboratory Standards Institute.

Deshpande, L. M., Fritsche, T. R., Moet, G. J., Biedenbach, D. J. \& Jones, R. N. (2007). Antimicrobial resistance and molecular epidemiology of vancomycin-resistant enterococci from North America and Europe: a report from the SENTRY antimicrobial surveillance program. Diagn Microbiol Infect Dis 58, 163-170.

Donabedian, S., Hershberger, E., Thal, L. A., Chow, J. W., Clewell, D. B., Robinson-Dunn, B. \& Zervos, M. J. (2000). PCR fragment length polymorphism analysis of vancomycin-resistant Enterococcus faecium. J Clin Microbiol 38, 2885-2888.

Falagas, M. E. \& Vardakas, K. Z. (2008). Benefit-risk assessment of linezolid for serious Gram-positive bacterial infections. Drug Saf 31, 753-768.

Garcia-Garrote, F., Cercenado, E. \& Bouza, E. (2000). Evaluation of a new system, VITEK 2, for identification and antimicrobial susceptibility testing of enterococci. J Clin Microbiol 38, 2108-2111.

Gonzales, R. D., Schreckenberger, P. C., Graham, M. B., Kelkar, S., DenBesten, K. \& Quinn, J. P. (2001). Infections due to vancomycinresistant Enterococcus faecium resistant to linezolid. Lancet 357, 1179.

Jones, R. N., Fritsche, T. R., Sader, H. S. \& Ross, J. E. (2007). LEADER surveillance program results for 2006: an activity and spectrum analysis of linezolid using clinical isolates from the United States (50 medical centres). Diagn Microbiol Infect Dis 59, 309-317.

Kobayashi, I., Muraoka, H., lyoda, T., Nishida, M., Hasegawa, M. \& Yamaguchi, K. (2004). Antimicrobial susceptibility testing of vancomycin-resistant Enterococcus by the Vitek system, and comparison with two NCCLS reference methods. J Med Microbiol 53, 12291232.
Lee, W. G., Huh, J. Y., Cho, S. R. \& Lim, Y. A. (2004). Reduction in glycopeptide resistance in vancomycin-resistant enterococci as a result of vanA cluster rearrangements. Antimicrob Agents Chemother 48, 1379-1381.

Linden, P. K. (2002). Treatment options for vancomycin-resistant enterococcal infections. Drugs 62, 425-441.

Marshall, S. H., Donskey, C. J., Hutton-Thomas, R., Salata, R. A. \& Rice, L. B. (2002). Gene dosage and linezolid resistance in Enterococcus faecium and Enterococcus faecalis. Antimicrob Agents Chemother 46, 3334-3336.

NNIS (2001). National Nosocomial Infections Surveillance (NNIS) System Report, data summary from January 1992-June 2001, issued August 2001. Am J Infect Control 29, 404-421.

Park, I. J., Lee, W. G., Shin, J. H., Lee, K. W. \& Woo, G. J. (2008). VanB phenotype-vanA genotype Enterococcus faecium with heterogeneous expression of teicoplanin resistance. J Clin Microbiol 46, 3091-3093.

Pendle, S., Jefts, P., Olma, T., Su, Y., Gilroy, N. \& Gilbert, G. L. (2008). Difficulties in detection and identification of Enterococcus faecium with low-level inducible resistance to vancomycin, during a hospital outbreak. Clin Microbiol Infect 14, 853-857.

Rice, L. B., Hutton-Thomas, R., Lakticova, V., Helfand, M. S. \& Donskey, C. J. (2004). $\beta$-Lactam antibiotics and gastrointestinal colonization with vancomycin-resistant enterococci. J Infect Dis 189, 1113-1118.

Ruggero, K. A., Schroeder, L. K., Schreckenberger, P. C., Mankin, A. S. \& Qiunn, J. P. (2003). Nosocomial superinfections due to linezolidresistant Enterococcus faecalis: evidence for a gene dosage effect on linezolid MICs. Diagn Microbiol Infect Dis 47, 511-513.

Scheetz, M. H., Qi, C., Noskin, G. A, Warren, J. R., Postelnick, M. J., Malczynski, M., Huang, J. \& Zembower, T. R. (2006). The clinical impact of linezolid susceptibility reporting in patients with vancomycin-resistant enterococci. Diagn Microbiol Infect Dis 56, 407-413.

Tenover, F. C., Williams, P. P., Stocker, S., Thompson, A., Clark, L. A., Limbago, B., Carey, R. B., Poppe, S. M., Shinabarger, D. \& McGowan, J. E., Jr (2007). Accuracy of six antimicrobial susceptibility methods for testing linezolid against staphylococci and enterococci. J Clin Microbiol 45, 2917-2922.

Thal, L.-A., Donabedian, S., Robinson-Dunn, B., Chow, J. W., Dembry, L., Clewell, D. B., Alshab, D. \& Zervos, M. J. (1998). Molecular analysis of glycopeptide-resistant Enterococcus faecium isolates collected from Michigan hospitals over a 6-year period. J Clin Microbiol 36, 3303-3308.

van den Braak, N., Goessens, W., van Belkum, A., Verbrugh, H. A. \& Endtz, H. P. (2001). Accuracy of the VITEK 2 system to detect glycopeptides resistance in enterococci. J Clin Microbiol 39, 351-353. 